\title{
A cobertura dos protestos de 2013 e o seu reflexo na política de mobilidade urbana da cidade de São Paulo
}

The coverage of the 2013 protests and this reflection on the urban mobility policy of the city of São Paulo

\author{
Deborah Ramos da Silva - UNESP | Bauru | São Paulo | Brasil | E-mail: \\ deborahme192@gmail.com \\ ID ORCID
}

Paula Keiko Poloni - UFABC | Santo André| São Paulo | Brasil | E-mail: paula.keiko@ufabc.edu.br (D) ORCID

Maria Teresa Miceli Kerbauy - UNESP| Araraquara| São Paulo | Brasil | E-mail: kerbauy@travelnet.com.br

Resumo: Este artigo apresenta resultados de pesquisa realizada com o objetivo de gerar conhecimento científico sobre a qualidade das informações ofertadas pelos dois maiores veículos da cidade de São Paulo, Folha de S. Paulo e o Estado de S. Paulo em junho de 2013, quando o Brasil foi surpreendido por um grande número de manifestações de rua, totalizando 234 matérias no período de 7 a 21 de junho de 2013, ápice dos protestos. O estudo investigou, por meio da análise de conteúdo e revisão bibliográfica, de que forma a macromídia ou mídia convencional cobriu os protestos; além de apresentar como os dois principais jornais brasileiros online abordaram o tema e os atores envolvidos. Diante dos resultados, o estudo forneceu indicações de que apesar do cenário conflituoso, São Paulo soube aproveitar a oportunidade, pois a partir dele, o município criou um conselho para a área de transporte e trânsito na conjuntura dos Protestos.

Palavras-chave: Manifestações. São Paulo. Macromídia. Mobilidade. CMTT.

Abstract: This article presents results of a research carried out with the objective of generating scientific knowledge about the quality of the information offered by the two largest vehicles of the São Paulo city, Folha de S.Paulo and Estado de S. Paulo. In June 2013 when Brazil was surprised by a large number of street demonstrations, totaling 234 subjects in the period from June 7 to 21 in 2013 the height of the protests. The study investigated about through content analysis and bibliographic review how macromedia or conventional media covered the protests; as well as presenting how the two main Brazilian online newspapers addressed the theme and the actors involved. Given the results, the study provided indications that despite the conflictive scenario in São Paulo was able to seize the opportunity, because from it the municipality created a council for the area of transportation and transit in the conjuncture of the Protests.

Keywords: Manifestations. São Paulo. Macromedia. Mobility. CMTT.

- Recebido em 11 de fevereiro de 2019 • Aprovado em 01 de julho de 2019 • e-ISSN: 2177-5788

DOI: https://doi.org/10.22484/2177-5788.2019v45n1p87-106

Copyright @ 2019. Conteúdo de acesso aberto, distribuído sob os termos da Licença Internaonal da CreativeCommons - CC BY-NC-SA - Atribuição Não Comercial (https://br.creativecommons.org/licencas/) Permite distribuição e reprodução, desde que atribuam os devido créditos à publicação, ao autor(es) e que licenciem as novas criações sob termos idênticos. 


\section{Introdução}

Em 2013, a cidade de São Paulo foi palco de frequentes protestos que reuniram multidões, as quais, organizadas por meio das redes sociais, agruparam-se em suas praças e avenidas. Durante as manifestações, o Movimento Passe Livre (MPL) se tornou um emblema devido à expressão e forma política de agir. No entanto, deve-se ter em mente que o Movimento já dispunha de uma articulação nacional desde 2005, com ideias políticas difundidas por seus participantes em várias cidades. As manifestações do MPL não se reduziam apenas ao preço das passagens de ônibus, apesar de esta ter sido uma estratégia importante para o Grupo. De um modo mais abrangente, o Movimento se refere aos direitos do cidadão no que diz respeito à mobilidade urbana, que, em sua concepção, deveria ser considerado um direito fundamental, um serviço público essencial que assegure o acesso das pessoas aos demais direitos, como, por exemplo, saúde e educação. Partindo dessa premissa, o MPL propõe a desmercantilização do transporte coletivo, ou seja, a "tarifa zero" como o meio mais prático e efetivo de assegurar o direito de ir e vir de toda a população nas cidades.

Devemos relembrar que, na primeira passagem do Partido dos Trabalhadores (PT) pelo comando da prefeitura em 1990, o que ocorreria anos depois com Marta Suplicy em 2000 e Fernando em 2012, há uma das primeiras iniciativas no Brasil, por parte do poder público municipal, em estabelecer a tarifa zero para o transporte público:

Em 1990, a prefeita Luiza Erundina (à época no Partido dos Trabalhadores) encaminhou à Câmara Municipal de São Paulo um projeto, de autoria do secretário municipal de Transportes Lúcio Gregori, que ficou conhecido como "tarifa zero", e que até hoje é referência para os movimentos que lutam por um transporte público de qualidade como um direito social de todos (TAKEMOTO, 2014, p. 25).

Os recursos necessários à implementação da proposta viriam da cobrança progressiva do IPTU, sobretudo em imóveis que representassem atividade econômica, seja no comércio ou na indústria, e, também, daqueles que não estivessem contribuindo com a produção ou não possuíssem uma função social, além da criação de um fundo de transportes, conforme salienta Takemoto (2014). No entanto, "...a ideia não foi implementada devido à resistência política. Em cidades como a capital paulista, as empresas são remuneradas pelo número de passageiros, ou seja, lucram mais com ônibus cheios" (LOCATTELLI, 2013, p. 10). 
O projeto foi para a Câmara que não votou [...]. Não foi votado por uma disputa política e mexia com os interesses de pessoas que pagavam impostos relativamente baixos e passariam a pagar 0 imposto realmente necessário. Ninguém queria mexer neste vespeiro. O projeto foi arquivado, mas houve consequências. Ao negar-se a votar, a Câmara foi corresponsável por um estado calamitoso do transporte de São Paulo à época (GREGORI, 2013).

O próprio ex-secretário municipal de transportes da gestão Luiza Erundina, Lúcio Gregori, reconhece as dificuldades enfrentadas pelo projeto desde a tentativa de implementação, quando o Executivo dependia da aprovação da medida pelo Legislativo. A fala de Gregori (2013) demonstra a dificuldade que o Estado tem de garantir e melhorar, no Brasil, a qualidade dos serviços públicos baseado, em parte, no aumento de impostos para a parcela da população de maior poder aquisitivo.

E, apesar de a cidade de São Paulo não ter conseguido implantar a tarifa zero nos transportes públicos, em algumas cidades do Brasil a experiência já é adotada, embora um número ínfimo diante do total de 5.564 municípios brasileiros, tendo as cidades de Agudos (SP), Ivaiporã e Pitanga (PR) adotado o passe livre irrestrito, custeado pelas respectivas prefeituras. Além destas cidades, no Estado do Rio de Janeiro, no ano de 2011 , o município de Porto Real aboliu a tarifa no valor de $\mathrm{R} \$ 0,50$ e instituiu o Passe Livre irrestrito; e, em dezembro de 2014, portanto mais de um ano após o início das manifestações convocadas pelo MPL, a cidade de Maricá $(\mathrm{RJ})$, adotou a tarifa zero.

O principal argumento da maioria dos prefeitos em todo país, para não instituir a tarifa zero, é que o custo da iniciativa é incompatível com os orçamentos das prefeituras, sobretudo por não haver alguma complementação financeira por parte dos Estados ou da União; além de, em algumas cidades, as prefeituras já subsidiarem o transporte público por financiarem diretamente a gratuidade das passagens de segmentos da população como estudantes, desempregados, idosos e deficientes físicos, como destaca o presidente do Frente Nacional dos Prefeitos (FNP) ao ser questionado em uma entrevista sobre a proposta de Passe Livre irrestrito.

Nós da Frente Nacional de Prefeitos procuramos realizar vários cenários. [...] O senador Renan Calheiros [PMDB-AL] tinha uma proposta sobre isso. Buscamos assessoria técnica. Estivemos no Poder Executivo federal, discutimos com o Ministério da Fazenda. E chegamos à conclusão que passe livre de forma ampla seria algo absolutamente impensável. Não existem recursos para que isso aconteça. Nós propusemos, e achamos que é uma proposta razoável, o chamado passe livre com corte social. Poderíamos atender desempregados, donas de casa, estudantes com um limite de renda. O impacto no país poderia chegar a $R \$ 3$ bilhões, o que seria até adequado, desde que financiado pelo governo federal. Os municípios não têm como fazer isso (FORTUNATI, 2014). 
Há também outros condicionantes que, segundo Vasconcellos (2013), inviabilizariam a implantação da tarifa zero. No tocante à operacionalização do sistema, restaria ao município escolher entre dois modelos: o primeiro de continuidade de operação das atuais e de novas empresas, sendo remuneradas diretamente pelo município, o que poderia levá-las a não se responsabilizarem mais pela qualidade do serviço. Já o segundo implicaria a criação de empresas municipais de transportes, para operar o sistema de transporte.

Neste contexto, observa-se que a mobilidade urbana, acessibilidade e políticas públicas de transporte voltaram à agenda da sociedade paulistana, em especial envolvendo a Região Metropolitana de São Paulo, a partir das demandas sociais deflagradas pelo MPL.

É importante ressaltar que, no art. 30, inc. V, da Constituição Federal de 1988, a organização e a prestação do transporte coletivo é de competência exclusiva dos municípios, embora o art. 21, inc. XX reserve a competência da União para instituir as diretrizes nacionais para o setor.

Desta forma, àquele movimento passou, assim, a ocupar a atenção da mídia a partir de pautas vinculadas à garantia do acesso ao transporte público coletivo, com a bandeira da redução tarifária, considerando a escassez financeira da população de arcar com os custos das tarifas dos serviços.

Todavia, historicamente, esse não é um tema novo. Gomide e Galindo (2013, p. 28) já afirmavam que:

\begin{abstract}
O processo de urbanização acelerada e desorganizada resultante da industrialização por substituição de importações - aprofundada pelos governos autoritários pós-1964 - refletiu-se nos problemas de transporte urbano, sobretudo na década de 1970. À época, a maior parte da população trabalhadora era dependente dos meios coletivos de transportes, a despeito do crescimento da indústria automobilística. Grosso modo, o crescimento das taxas de deslocamentos urbanos apresentava taxas duas vezes maiores do que o próprio crescimento urbano, que já era alto.
\end{abstract}

Além disto, também o conceito de mobilidade urbana tem sido discutido há certo tempo, não havendo uma definição única uniforme.

Segundo o Tribunal de Contas da União (BRASIL. TCU), mobilidade urbana é o "deslocamento de pessoas e bens dentro do espaço das cidades, mediante utilização de veículos, de vias públicas e da infraestrutura disponível" (2010, p. 410) e, além disso, seu conceito:

se apoia em quatro pilares: (i) integração do planejamento do transporte com o planejamento do uso do solo; (ii) melhoria do transporte público de passageiros; (iii) estímulo ao transporte não motorizado e (iv) uso racional do automóvel (BRASIL. TRIBUNAL DE CONTAS DA UNIÃO, 2010, p. 410). 
Kneib (2012, p. 71), por sua vez, apresenta a mobilidade urbana unicamente "como sinônimo de transporte", havendo hoje

um consenso de que a busca por uma mobilidade urbana de maior qualidade, ou mais sustentável, deve considerar uma série de variáveis que impactam os deslocamentos nas cidades, e deve basear-se na priorização e valorização dos modos coletivos e não motorizados de transporte.

A par disso, ao considerar o transporte como sendo um direito social (art. 60, da Constituição Federal de 1988), pode-se considera-lo também como sendo uma questão de política pública?

As políticas públicas devem ser compreendidas como esquemas de aglutinação de conhecimentos e instrumentalização de ações mais adequada às demandas de efetivação constitucional, conforme entende Bucci (2009), especialmente considerando a qualidade da política de transporte, análise de estratégia, planejamento governamental e compartilhamento de novas políticas, com caráter inovador e práticas de gestão.

Dworkin (2002) tentou definir o que são questões políticas, diferenciando-as de princípios. Os argumentos de política justificam uma decisão política, demonstrando que a decisão incentiva ou protege algum objetivo coletivo da comunidade como um todo. O argumento em favor de um subsídio para a indústria aeronáutica que apregoa que tal subvenção irá proteger a defesa nacional, por exemplo, é um argumento de política ${ }^{1}$.

De acordo com Dworkin (2002, p. 148), os argumentos de princípios justificam uma decisão política, demonstrando que a decisão respeita ou garante um direito de um indivíduo ou de um grupo. Assim, por exemplo, um argumento em favor das leis contra a discriminação, segundo o qual uma minoria tem direito à igualdade de consideração e respeito, é um argumento de princípio.

\footnotetext{
${ }^{1}$ Los argumentos políticos justifican una decisión política demostrando que favorece o protege alguna meta colectiva de la comunidad en cuanto todo. El argumento en favor de un subsidio para los fabricantes de aviones, que afirma que con él se protegerá la defensa nacional, es un argumento político. Los argumentos de principio justifican una decisión política demostrando que tal decisión respeta o asegura algún derecho, individual o del grupo. El argumento a favor de las leyes que se oponen a la discriminación (racial en los Estados Unidos), y que sostiene que una minoría tiene derecho a igual consideración y respeto, es un argumento de principio.
} 
Segundo Barboza e Kozicki (2012, p. 72):

Dessa definição poder-se-ia deduzir que o conceito de política pública (policy) diz respeito a metas coletivas, objetivos sociais que demandam programas de ação pelos Poderes Públicos, comum num Estado que se pretende social. Já os princípios estariam mais relacionados a proteções de direitos individuais.

Entretanto, Bucci (2009, p. 10) alerta que:

As políticas públicas não se confundem com os direitos. Por essa razão, salvo excepcionalmente, a Constituição não contém políticas públicas, mas direitos, cuja efetivação, especialmente no caso dos direitos econômicos, sociais e culturais, ditos, elipticamente, sociais, depende das políticas públicas.

[...] os direitos sociais não são políticas públicas nem devem ser confundidos com elas. São direitos fundamentais, cuja satisfação integral requer programas, recursos públicos, os quais, em circunstâncias de escassez, são alocados segundo a dinâmica política, que combina tempo e definição de prioridades (BUCCI, 2009, p. 10).

Portanto, segundo Bucci (2009), o transporte público ou coletivo enquanto direito social não se confunde com políticas públicas, mas podese relacioná-lo as estas uma vez que elas se caracterizam como programas de ações governamentais que buscam a realização de metas coletivas como um todo, especialmente na área social, como acontece com o pleno emprego, saúde pública, moradia etc.

Com este resgaste conceitual, por outro lado, dentre os veículos de comunicação que cobriram os protestos na capital paulistana, destacam-se os jornais Folha de S. Paulo e O Estado de S. Paulo, por terem publicado, durante os protestos de junho, várias matérias sobre o MPL e a sua atuação durante as manifestações, propiciando ao leitor, pelo menos em tese, a oportunidade de se aprofundar sobre a história do movimento, sua composição, suas reivindicações e os resultados das reuniões entre o MPL e as autoridades após o início dos protestos para discutirem a pauta da mobilidade, uma vez que as mensagens transmitidas pela indústria da mídia são recebidas por pessoas específicas, situadas em contextos sócio históricos específicos. Essas pessoas veem "as mensagens dos meios com graus diferenciados de concentração, interpretam-nas ativamente e dãoIhes sentido subjetivo, relacionando-as a outros aspectos de suas vidas". (THOMPSON, 1998, p. 287).

Neste estudo, a partir da ideia de Menezes (2010, p. 19) de que os veículos de comunicação "seriam os responsáveis por pautar a agenda pública, embora em alguns momentos haja um contra-agendamento e a própria sociedade paute esses meios de comunicação", aliada ao fato deste trabalho buscar estudar, a partir da cobertura midiática, um movimento 
social que ganhou a atenção nacional a partir de um evento político e social recente na história brasileira, apresentamos uma análise da forma como as jornadas de junho de 2013 foram enquadradas pelos jornais online Folha de S. Paulo e O Estado de S. Paulo, assim como verificamos que o Conselho Municipal de Transporte e Trânsito (CMTT) configurou-se como um espaço de participação e controle social que veio ao encontro das demandas que levaram milhares de cidadãos a se manifestarem, adotando como metodologia a análise de valências e enquadramentos, desenvolvida por pesquisadores do Laboratório de Pesquisa em Comunicação Política e Opinião Pública (DOXA) do Instituto de Estudos Sociais e Políticos do Rio de Janeiro (IESP- UERJ). Utilizamos ainda, durante a pesquisa, a definição de Almeida (2015, p. 52) para definir os veículos de larga escala:

\begin{abstract}
Macromídia aquela mídia que possui longo alcance, geralmente transmitindo sua produção via broadcasting com foco nos grandes públicos, que integra o mainstream midiático. Sua influência pode ser local, nacional ou internacional e possui grande poder de interferência na agenda pública e política. Sua produção segue modelo industrial, além de possuir uma estrutura técnica e tecnológica robusta.
\end{abstract}

Já a análise de 234 matérias teve como base os estudos do enquadramento. Para tanto, considerou-se que, segundo Motta (2010), os diversos enquadramentos dados na edição das notícias não são acidentais, mas, antes, premeditados. Com o intuito de evidenciar o enquadramento utilizado pelos dois maiores jornais de São Paulo no tocante às manifestações, foram analisadas as matérias publicadas pelos veículos no período de 7 a 21 de junho. Tal recorte temporal foi estabelecido uma vez que o primeiro dia das manifestações foi em 6 de junho, pois as publicações que trataram sobre os atos começaram a surgir a partir desse momento e seguiram até o dia 21 do mesmo mês. O período se mostrou ideal, uma vez que comporta os principais eventos das Jornadas de Junho até a referida data, tais como os primeiros protestos; a repercussão da repressão policial; a intensificação das passeatas e sua nacionalização; o início da Copa das Confederações da FIFA, que se tornou o foco dos protestos em sua segunda fase; e, finalmente, o anúncio da redução da tarifa em São Paulo e em diversas cidades. Na prospecção desse recorte temporal, concluiu-se que havia um quantitativo seguro e expressivo de matérias.

\title{
2 Jornalismo na era da Informação
}

Nos protestos de junho de 2013, que levaram milhões de pessoas às ruas do Brasil, a estrutura midiática foi uma das temáticas mais evidenciadas, com movimentos populares e manifestantes que pediam a democratização da mídia. Essa estrutura tem, por um lado, os conglomerados de comunicação, pertencentes a algumas poucas famílias e que produzem a maior parte da informação que circula no país. De outro, apresenta uma formação discursiva, organizacional e teórica distinta, que 
trata de uma grande quantidade de pequenos meios, os quais constituem o campo da mídia alternativa, vinculada em maior ou menor medida aos movimentos populares, com discurso à esquerda e buscando transformações sociais nos mais variados campos.

Cumpre relembrar que os protestos de junho de 2013 surgiram, inicialmente, para contestar o aumento de $R \$ 0,20$ na tarifa de transporte público em São Paulo. Mas os atos foram ganhando apoio popular, o que elevou a pauta de reivindicações. Como consequência, Frederico (2013, p. 252) afirma que o indivíduo ficou "enredado no campo dominado pela mídia", que visava "pautar a conduta individual". Tanto que "não foi por mero acaso que a palavra de ordem gritada nas ruas - 'vem pra rua, vem' - tenha replicado o slogan da propaganda de uma marca de carros que então era veiculada exaustivamente na televisão" (FREDERICO, 2013, p. 252).

Para Traquina (2014, p. 24), "dois polos começaram a tornar-se dominantes na emergência do campo jornalístico contemporâneo: o pólo econômico (a definição das notícias como um negócio) e o polo ideológico (a definição das notícias como um serviço público)". Portanto, podemos analisar o jornalismo como uma instância de poder e de produção de sentido perante a opinião pública, que possui relações imbricadas com os poderes estabelecidos, que Ihes financiam e agem para que esses interesses sejam preservados com a manutenção do status quo:

\begin{abstract}
O campo jornalístico age, enquanto campo, sobre outros campos. Em outras palavras, um campo, ele próprio cada vez mais dominado pela lógica comercial, impõe cada vez mais suas limitações aos outros universos. Através da pressão do índice de audiência, o peso da economia se exerce sobre a televisão, e, através do peso da televisão sobre o jornalismo, ele exerce sobre os outros jornais, mesmo sobre os mais "puros", e sobre jornalistas, que pouco a pouco deixam que problemas de televisão se imponham a eles. E, da mesma maneira, através do peso do conjunto do campo jornalístico, ele pesa sobre todos os campos de produção cultural (BOURDIEU, 1997, p. 81).
\end{abstract}

Não se pretende, nesse estudo, partir de uma visão catastrófica da mídia e seu controle sob a sociedade, mas, de fato, o avanço das tecnologias da informação e comunicação e a consequente bidirecionalização dos fluxos informacionais provocados pela comunicação em rede promoveram alterações em alguns sólidos valores do jornalismo, conforme veremos mais à frente. Assim, o próprio jornalismo foi deslocado do centro dos processos informacionais. A prática jornalística passou a sofrer ressignificações no momento em que teve de se adequar ao ambiente da Internet, às funcionalidades das mídias digitais e às novas formas de consumo e produção de informação.

Sem dúvida, as novas ferramentas digitais colaboram para reestruturar o exercício da profissão, a produção industrial da notícia, as 
relações entre as empresas de comunicação com as fontes, a audiência, os concorrentes, o governo e a sociedade. Trazem, com isso, implicações de ordem técnica, ética, jurídica e profissional para o jornalismo.

Entretanto, apesar das mudanças abrangentes, há uma tendência corrente em estudá-las como se fossem de caráter meramente operacional. Ressalta-se como um dos seus efeitos a readaptação legitimadora das rotinas produtivas e de linguagens às exigências da instantaneidade e da visualidade do jornalismo online. Entre pesquisadores como Kunczik (2001), Kovack e Rosentiel (2003), Ramonet (2012) e Wolton (1999), há certo consenso quanto à influência das tecnologias da informação na reestruturação da organização jornalística e de suas rotinas de trabalho.

A informática como tecnologia, especialmente, trouxe agilidade e qualidade no processamento da informação, ao facilitar o trabalho de rever, corrigir, alterar e atualizar textos.

No entanto, os pesquisadores mencionados duvidam que as tecnologias digitais tenham provocado mudanças profundas na concepção de jornalismo, a ponto de alterar valores consagrados. Na avaliação de Wolton (1999, p. 268-269), por exemplo, a imprensa continua a mesma, ou seja, "a mudança foi apenas de forma, de linguagem, que em nada abalou os princípios basilares do jornalismo". Por mais forte que seja uma inovação tecnológica não leva consigo, mecanicamente, uma transformação profunda do conteúdo das atividades.

Podemos considerar esse argumento parcialmente válido. No entanto, é necessário considerar, para melhor compreensão, que a essência da natureza das tecnologias da informação de hoje, especialmente a Internet, difere radicalmente de outras do passado e sua influência pode carregar transformações de valores e conceitos. Para o jornalismo, a adoção dessas tecnologias da informação sinaliza mudanças que não ficam apenas no nível da troca de roupagem, sendo bem mais profundas do que muitos pesquisadores costumam analisar, podendo até mesmo solapar valores fundadores dessa práxis social.

O correto é que no jornalismo em geral e no webjornalismo, em particular, podemos nos referir à existência de um método próprio de trabalho. Método este que diz respeito a um conjunto de regras procedimentais de apuração de um fato, baseadas em valores e concepções sobre o papel e as formas de atuação jornalística, que visam atingir um determinado fim (produzir notícias) sobre fatos e opiniões considerados de interesse público ou diversionais.

Portanto, falar em método de apuração jornalística significa falar de um conjunto de práticas (habilidades e técnicas) executadas pelos jornalistas, como por exemplo, a observação de eventos e de seus desdobramentos, entrevista com fontes de informações, leitura de documentos e outros dados de natureza técnica, etc. 
Entretanto, não custa lembrar que ao longo do tempo o jornalismo se tornou uma atividade coletiva, organizacional e industrial, que exige do repórter uma operacionalidade nos seus atos e objetivos, expressa em uma pauta pré-definida, balizada por parâmetros de avaliação da noticiabilidade dos eventos e cuja execução é controlada por outros jornalistas.

Nessa lógica, a produção com poucos recursos em períodos exíguos de tempo para uma publicação cada vez mais acelerada conduz a uma simplificação do método de trabalho jornalístico e por vezes acaba por limitar a capacidade de captar e verificar informações. É a partir desta crítica ao "positivismo" presente numa proposta de um jornalismo de precisão de base quantitativa, que pesquisadores sociais de matriz qualitativa consideraram necessário rever tanto os modos tradicionais de reportagem jornalística, quanto as contribuições que as ciências sociais quantitativas poderiam trazer à atividade.

Com essa preocupação os jornalistas, bem como os pesquisadores em comunicação, viram-se forçados a ampliar o grau de validação de seus estudos o que os estimulou a combinarem métodos de trabalho, sejam de base qualitativa ou quantitativa. Esta combinação pode ocorrer simultaneamente nas reportagens, buscando confrontar os dados oriundos de diferentes fontes para que se complementem e permitam conclusões mais precisas. Um exemplo ilustrativo desta combinação de abordagens é o uso que o jornal Folha de S. Paulo faz do Instituto de Pesquisa Datafolha, pertencente ao mesmo Grupo Folha da Manhã, para levantar dados eleitorais e situações sociais complexas. Para isso, a atividade jornalística depende da composição de uma equipe multidisciplinar para pesquisa e interpretação dos dados eleitorais.

\section{Os Enquadramentos de 2013}

Sob essa perspectiva, apresentamos os enquadramentos jornalísticos que foram trabalhados por Tuchman (1980, p. 1), para quem "as notícias são uma janela para o mundo. [...] A panorâmica através de uma janela depende de esta ser larga ou estreita, de ter muitas ou poucas traves, do vidro ser opaco ou transparente, do facto de a janela dar para uma rua ou para um quintal". A autora considera que a produção de notícias constitui um ato de construção da realidade, e não uma imagem da realidade. Essa reflexão é partilhada por vários investigadores, sendo recorrente em muitos estudos: "Embora as notícias não sejam ficção, são uma 'estória' sobre a realidade, não a realidade em si" (BIRD; DARDENNE, 1999, p. 276).

Os enquadramentos são, portanto, padrões comuns ao processo de construção das notícias. O que jornalistas podem fazer é esforçar-se para promover diversidade nos enquadramentos, nas interpretações promovidas por fontes e pelos próprios jornalistas. Deste modo, é importante analisar quais enquadramentos são utilizados nas coberturas de eventos e temas políticos. 
Porto (2004) divide os enquadramentos entre noticiosos e interpretativos. Como explica o autor, existem na literatura corrente diversos conceitos de enquadramento, como o de Tuchman (1980); Gitlin (1980); Goffman (1986); Gamson e Wolfsfeld (1993) e Entman (1993), entre outros, que tocam em diversos níveis de análise. Alguns autores, como Maher (2001), distinguem entre enquadramento da mídia, criados pelos jornalistas, e enquadramentos culturais, que existem no plano externo aos jornalistas, diga-se na cultura.

Neste trabalho, utilizamos a definição proposta por Porto (2004, p. 92), de que "os enquadramentos noticiosos são consequência de escolhas feitas por jornalistas quanto ao que evidenciar em uma realidade percebida".

Identificamos durante a pesquisa, as recorrências lexicais tanto de $\mathrm{O}$ Estado como da Folha. O primeiro, utilizou mais o termo lexical "depredação", ocorrendo em quase $16 \%$ das matérias, das 72 desse veículo, o que sugere uma cobertura voltada aos danos ao patrimônio público e privado.

Destacamos ainda outras duas escolhas - "confrontos" e "violência" -, que ocorreram respectivamente em $15 \%$ e quase $12 \%$, conferindo aos atos um caráter bélico. No entanto, notamos que, apesar da utilização de termos que indiquem uma repressão da polícia militar demandada pela imprensa e da detenção de diversos manifestantes, os léxicos "medo" e "revolta" são os dois menos usados - cerca de $1 \%$. Em linhas gerais, as recorrências lexicais de $\mathrm{O}$ Estado de $\mathrm{S}$. Paulo foram baixas, indicando que o veículo não explorou as palavras de carga negativa, o que demonstra o uso de um vocabulário mais diversificado para transmitir os fatos aos seus leitores.

Por fim, ao analisar os jornais concorrentes da capital, percebe-se que O Estado de S. Paulo foi menos recorrente em suas escolhas lexicais de carga simbólica negativa do que a Folha de S. Paulo, devido, por exemplo, à diferença entre os termos mais usados por cada um: "depredação", com pouco mais de $15 \%$ pelo Estado, e "confrontos", com pouco mais de $35 \%$ pela Folha.

Apesar disso, houve um grande uso por ambos de palavras que evidenciavam os enfrentamentos entre polícia e manifestantes, como "confrontos", "depredação", "vandalismo" e "violência", sendo essas palavras as mais usadas pelos jornais, conforme pode ser notado no gráfico 1. 


\section{Gráfico 1 - Comparativo entre recorrências lexicais negativas dos dois veículos}

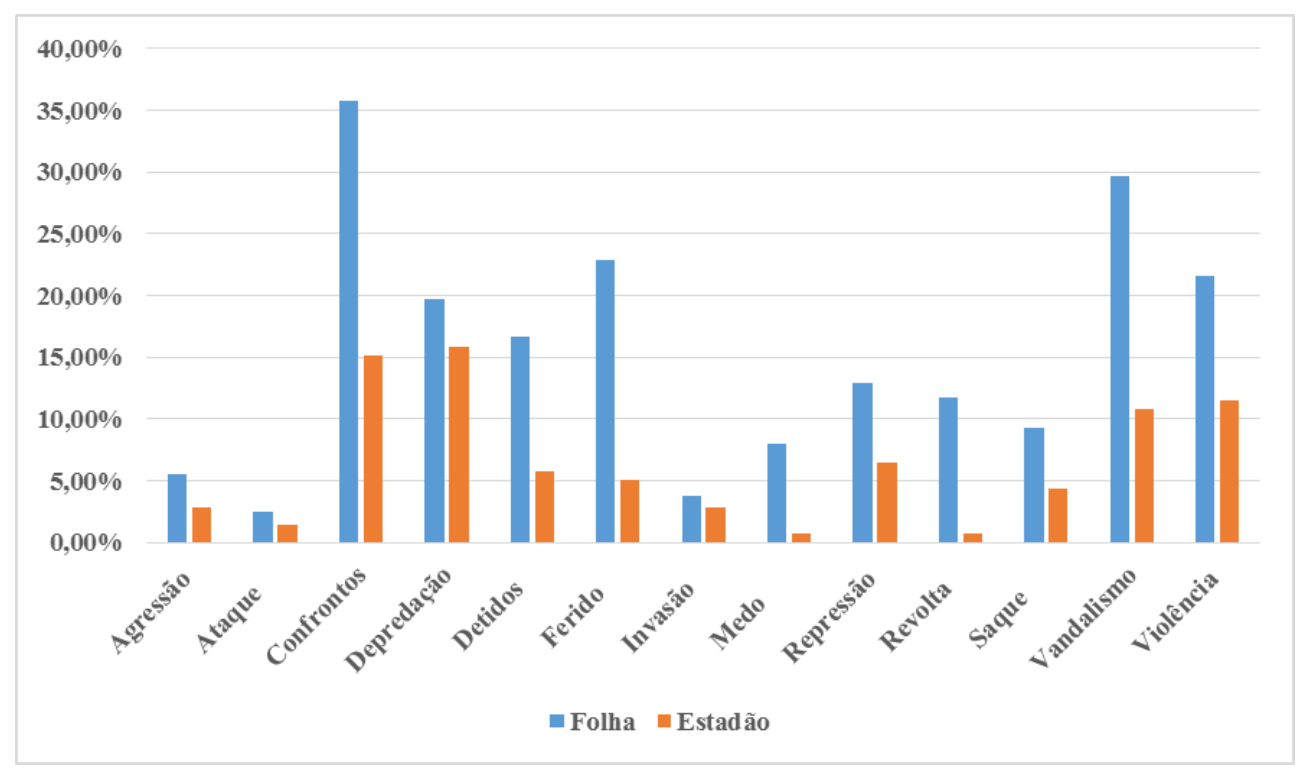

Fonte: Elaboração própria, a partir das matérias veiculadas nos dois jornais analisados neste estudo.

Em Comunicação, o framing ou enquadramento, como preferem alguns teóricos, começou a ser utilizado em pesquisas sobre como os movimentos sociais, principalmente os estudantis dos anos 1960, eram tratados pela mídia e como esse tratamento deveria ser modificado a fim de que atraísse a atenção e o apoio de uma parcela maior da população.

Atualmente, a teoria do enquadramento serve para identificar como os produtores de notícias selecionam e, mais do que isso, interpretam os conteúdos veiculados. Conforme Sádabra (2007), as fontes utilizadas pelos jornalistas também exercem influência sobre a realidade por eles construída:

\footnotetext{
Os jornalistas utilizam frames narrativos, porque eles facilitam sua tarefa de enquadrar a complexidade do mundo. Consciente ou inconscientemente, os jornalistas sabem que esses frames dramáticos são rapidamente compreendidos pelos receptores que os utilizam frequentemente no mundo da vida. São, portanto, definidores prévios da situação de comunicação que se vai estabelecer. Frames de recíproca interação através dos quais os interlocutores tornam possível a comunicação jornalística (MOTTA, 2007, p. 1).
}

Através da escolha de "aspas", o repórter também pode promover determinadas interpretações em detrimento de outras. Como explica Tuchman (1980, p. 81-82): 
[...] os jornalistas veem as citações de opiniões de outras pessoas como uma forma de prova suplementar. [...] Ao acrescentar mais nomes e citações, o repórter pode tirar as suas opiniões da notícia, conseguindo que os outros digam o que ele próprio pensa.

As fontes podem ser utilizadas, portanto, para corroborar as opiniões do repórter. No processo de construção da notícia, a seleção de aspas e argumentos funciona também como seleção de interpretações.

Percebemos, que de acordo com as informações do gráfico 2, que a Folha não destacou os Black Blocs (2\%) e os Punks (1\%) durante a cobertura, embora ambos tenham participado dos atos desde o início, passando, depois, a serem "personas non gratas" nas manifestações. 0 Estado também não citou à exaustão os Black Blocs (2\%) e os Punks (2\%).

Em junho de 2013, os Black Blocs atacaram principalmente bancos e agências de concessionárias de carros de grandes fabricantes, além de diversos prédios públicos; entre os mais emblemáticos, ocorreu uma quase invasão do prédio da Prefeitura de São Paulo e do Palácio do Itamaraty, em Brasília. Houve também tática de ação nas ruas, conforme ocorria a evolução dos protestos. No início do movimento, suas ações estavam voltadas para as passeatas e o confronto direto com a polícia. Após os protestos ganharem projeção nacional, os mesmos a se desligaram das ações do MPL e utilizaram táticas mais agressivas, atacando bancos, prédios públicos e aparatos da mídia tradicional.

Gohn (2014) chama atenção para a necessidade interpretar os Black Blocs como um movimento de alcance internacional. Suas práticas, desde o surgimento, se reproduzem em vários lugares do mundo. Como repudiam as formas de democracia representativa, adotam ação direta como sua forma de luta - o que inclui a violência. Mas, o mesmo autor destaca que há na sua forma de ação um tipo de reinterpretação da violência. Considerada defensiva e para proteger os manifestantes, os adeptos da tática veem na sua violência uma resposta, uma reação, e não um ataque. A autora fala em violência performática, que mistura elementos interativos, comunicativos e simbólicos de forma a configurar algo além de atos de desobediência civil. Afirma: "Há uma recusa à ordem estabelecida, há contestação política, há um questionamento do sistema vigente. Há uma identidade coletiva dialógica que focaliza no ato violento e realização da ação" (GOHN, 2014, p. 59). Em resumo, de acordo com a autora, eles se apresentam como uma tática de protesto baseada na ação direta e marcada por uma estética particular: roupas pretas e rostos semicobertos.

Assim como os Black Blocs, os Anarcopunks foram uma novidade em termos de exposição de um grupo quase desconhecido durante os protestos de 2013. O retorno dos punks, em suas diversas vertentes, também foi uma surpresa, desta vez, por ser um grupo altamente conhecido que estava fora das coberturas e notícias de protestos sociais há um bom tempo, até que os Black Blocs (cuja indumentária é inspirada em grupos anarcopunks) 
ganharam visibilidade e reabriram esse espaço. Tais grupos foram mais atuantes nas grandes capitais, principalmente em São Paulo, Rio de Janeiro, Belo Horizonte e Brasília, e receberam força à medida que as manifestações ganharam volume e massificação.

Por se tratar de um grupo que não possui liderança constituída, até porque não se propõe a participar de qualquer tipo de negociação, torna-se um alvo fácil para generalizações e especulações acerca de seus atos e, algumas vezes, pode até ser incitado ou manipulado por grupos que desejam desviar a atenção dos movimentos por meio das ações violentas dos grupos anárquicos.

A falta de informação também contribui para colocar, sob um mesmo guarda-chuva, os Black Blocs, Anarcopunks, movimentos antissistêmicos, vândalos e saqueadores. Como foi o caso do relatório da polícia ${ }^{2}$, divulgado à época, o qual apontava: "Punks que partem para o quebra-quebra são arregimentados por militantes do PSOL com o objetivo de desgastar o PT, do prefeito Haddad e o PSDB, do Governador Geraldo Alckmin" em avaliação feita por policiais infiltrados.

Destacamos que, após os protestos ganharem projeção nacional, os Black Blocs se "descolaram" das ações do MPL e utilizaram sua tática mais agressivamente, atacando bancos, prédios públicos e aparatos da mídia tradicional. Foi quando a tática passou a ser criminalizada pela imprensa e pelo poder público, que, contudo, não podia reagir de forma violenta dada a repercussão negativa dos excessos cometidos pela polícia nos primeiros dias.

${ }^{2}$ CARVALHO, Mario Cesar. Serviço secreto da PM diz que Psol 'recruta' punks. Disponível em: $\quad$ https://www1.folha.uol.com.br/cotidiano/2013/06/1295714-servico-secreto-dapm-diz-que-psol-recruta-punks-para-protestos.shtml. Acesso em 02 de mar.2019. 


\section{Gráfico 2 - Quantidade de menções dos principais atores envolvidos por veículo}

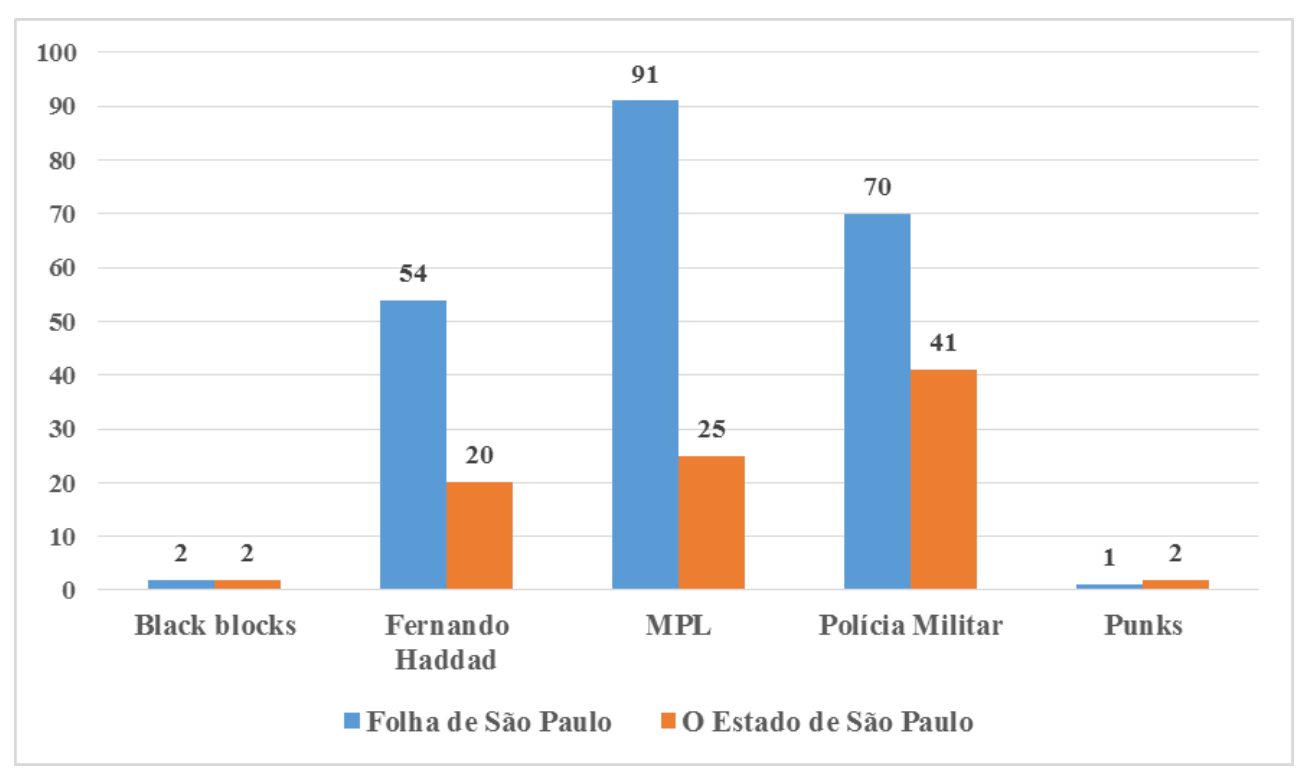

Fonte: Elaboração própria, a partir das matérias veiculadas nos dois jornais analisados neste estudo.

A partir dessa ideia, é coerente afirmar que, nesse processo envolvendo as formas simbólicas, a mídia vai buscar criar imagens, do ponto de vista sociopolítico, que ela tem interesse que o seu público tenha acesso.

Dessa forma, acontecimentos da vida política, econômica, científica, cultural e até mesmo a vida íntima de indivíduos anônimos ou famosos ganham, na mídia, o caráter, muitas vezes, maniqueísta de bons e maus, ou seja, daqueles que são movidos por interesses supostamente escusos ou que vão de encontro ao que a própria mídia considera como normalidade, em contraposição àqueles que sofrem as consequências danosas.

Como pudemos observar ao analisar os dois maiores jornais de São Paulo, políticos e a mídia deixaram o lugar de protagonistas do espaço público de discussão e abriram espaço para as manifestações e a opinião pública que, mesmo em seu caráter difuso, tornaram os discursos mais dinâmicos talvez mais do que gostariam, esses conglomerados da mídia.

\section{Mobilidade para a Cidade}

O Conselho Municipal de Transporte e Trânsito (CMTT) foi criado pelo Decreto $n^{\circ}$ 54.058, de $1^{\circ}$ de julho de 2013, do prefeito Fernando Haddad. A criação por decreto ainda não possui a força institucional de uma lei, mas constitui um avanço em relação à Portaria no 40/2000, que era inferior em termos normativos.

De forma sucinta, apresentamos três fatores que, conforme aponta Barbosa (2018), foram essenciais para a criação do Conselho Municipal de Transporte e Trânsito de São Paulo, em 2013. 


\section{O primeiro fator foi o social: os Protestos de Junho de 2013.}

De acordo com Della Porta e Diani (2006), um protesto ${ }^{3}$ pode ser definido por sua capacidade de mobilizar a opinião pública por meio de formas pouco convencionais, que escapam à rotina, e de assim pressionar aqueles que tomam as decisões ou fazem as leis, consideradas injustas ou inadequadas.

Assim, podemos dizer que o Executivo Municipal soube aproveitar este cenário conflituoso, pois a partir dele, criou-se um conselho para a área de transporte e trânsito na conjuntura dos Protestos com reivindicações contra o aumento da tarifa de ônibus em São Paulo.

O segundo fator é institucional: a Política Nacional de Mobilidade Urbana, criada pela Lei no 12.587 de 2012, e, finalmente, o terceiro é político - a abertura da CPI dos Transportes.

Ainda, de acordo com Barbosa (2018), nos primeiros anos de sua atuação, o CMTT se consolidou como um importante espaço institucional de debate e participação, permitindo a conciliação de diversos interesses e efetuando a prestação de contas das ações planejadas e executadas pelo governo municipal. O Conselho possui como potencialidade a colocação da sociedade civil, da sociedade política e de grupos com interesses econômicos no mesmo espaço de diálogo e conflito, de modo a criar um mecanismo de pesos e contrapesos que produzem certo equilíbrio nas discussões.

Apesar de se atribuir a origem do CMTT a uma resposta da Prefeitura às manifestações de junho, é importante resgatar as discussões e tentativas anteriores de criação desta instituição participativa. A primeira referência encontrada é de 1967 na lei que criou a Secretaria Municipal de Transporte (SMT) e instituiu o Conselho Municipal de Transportes (COMUT) com atribuição de "apreciar e emitir parecer sobre planificação dos transportes no Município e demais questões técnicas".

Mesmo que, desde a década de 90, a Lei Orgânica do Município de São Paulo (LOM) prevê que conselhos participativos na cidade devem ser criados pelo Legislativo, apenas em 2006 o Projeto de Lei (PL) no 47/20066 tramitou na Câmara Municipal de São Paulo (CMSP) com a proposta de criação de um conselho participativo para transporte e trânsito, mas foi arquivado em seguida. Posteriormente, outros dois PLs também não

\footnotetext{
3 Para fins deste artigo, não iremos diferenciar conceitualmente os termos protestos, manifestações e jornadas, tratando-os como sinônimos, dado o uso de todos estes termos na literatura para designar o mesmo fato: os protestos de junho de 2013. Contudo, importa destacar que os protestos aqui não se caracterizaram como um ato revolucionário, pois, de acordo com Singer (2013), não questionaram os pilares da ordem. Gohn (2014a) e Xavier (2013) também colocam que os manifestantes não negavam o Estado, mas reivindicavam um vínculo maior com as necessidades sociais.
} 
obtiveram sucesso: o PL no 296/20107, vetado pelo Prefeito; e o PL no $330 / 20118$, encerrado por descumprimento do regimento interno da casa legislativa.

Considerando o avanço da democracia participativa, de seus níveis de participação social e da sua influência eficaz na tomada de decisão, a democracia deliberativa se apresenta como uma etapa madura de participação, pois "todos os arranjos deliberativos são formas ampliadas de participação" (AVRITZER, 2000, p. 43).

Nesse sentido, Cohen (1997) defende a via da institucionalização da participação, que compreende o direito ao voto, associação, expressão política e direito de ser eleito, por acreditar que a legitimidade e a autoridade da democracia encontram-se quando o Estado toma decisões junto com integrantes da sociedade. Portanto, analisar a institucionalidade dos conselhos é essencial para conseguir identificar se no formato que eles se apresentam é possível que haja incidência nas políticas públicas, ou seja, se realmente seria possível a participação dos cidadãos nas decisões dos governos.

No entanto, quando o CMTT foi criado por Decreto do Poder Executivo definindo sua composição, atribuições e funcionamento, não houve audiência pública ou outro fórum de participação social para sua concepção. Logo na primeira reunião ordinária houve críticas do MPL sobre o caráter consultivo e não deliberativo do conselho, avaliando que esse modelo impede a gestão democrática, pois, de acordo com o MPL, a população deveria ter a possibilidade de participar da decisão.

Por isso, o que torna o CMTT frágil institucionalmente, de acordo com os parâmetros indicados por Lima et al. (2014) para determinar o nível de institucionalidade, é a falta de Lei específica e o fato de não ser deliberativo. O primeiro motivo enfraquece o funcionamento e a continuidade, pois quando há troca do governo municipal ou do chefe da pasta de mobilidade e transportes basta um ato do Executivo para extinguir ou alterar qualquer aspecto do conselho. O segundo, restringe a participação social e diminui o poder de influência do CMTT na política pública, pois a decisão de acatar as contribuições apresentadas pelas bancadas é exclusivamente do poder público.

\section{Considerações Finais}

A pesquisa revelou que, embora a Folha e o $\mathrm{O}$ Estado tenham noticiado a atuação do Movimento Passe Livre e inclusive dedicado matérias que explicavam o grupo aos seus leitores, essa cobertura se deu por meio da utilização de uma série de adjetivos e destaques da atuação do MPL que tinham muito mais a intenção de deslegitimar o movimento, enfatizar os danos ao patrimônio público e trazer pânico à população com um clima beligerante, conforme percebemos nas recorrências lexicais negativas dos dois veículos. 
A falta de pluralidade de temas e de veículos que compõem a macromídia é sintomática da relação entre mídia e movimentos sociais, pois em um país aonde persiste um nível de desigualdade elevado, é mais do que necessário que as lutas sociais tenham visibilidade perante toda população.

Dessa forma, os meios de comunicação, quando barram as tentativas de grupos em expor suas demandas, não estão permitindo que as pessoas possam exercer plenamente a cidadania. Ademais, a descrição detalhada sobre o processo de criação do CMTT no município contribuiu para constatar as dificuldades na institucionalização do conselho, uma vez que foram identificadas múltiplas tentativas dos governos municipais para instituí-lo ao longo do tempo. Igualmente, forneceu informações sobre a legitimidade de sua criação para além das manifestações de junho de 2013, estas que foram motivadas pelo aumento tarifário não conseguiram transferir o debate para esta instituição de participação, onde a sua atribuição de discutir alterações na tarifa de ônibus foi ignorada.

Ações tomadas por cada governo com posições contrárias de uma mesma política evidenciam a fragilidade do CMTT em incidir sobre a política de mobilidade urbana. Assim, é importante também chamar a atenção para que as fragilidades identificadas em relação à institucionalidade sejam fortalecidas e não conduzam a uma extinção do colegiado. Como apontado, bastaria um ato do Executivo para extinguir ou alterar qualquer aspecto do conselho.

\section{Referências}

ALMEIDA, Thiago D'angelo Ribeiro. Midiativismo e coberturas jornalísticas: mídias livres, movimentos em rede e estratégias de contrapoder. 2015. 165f. Dissertação (Mestrado em Ciências Sociais Aplicadas) - Universidade Federal da Paraíba, João Pessoa, 2015.

AVRITZER, Leonardo. Teoria democrática e deliberação pública. Lua Nova - Revista de Cultura Política, n. 50, p. 22-46, 2000. Disponível em:

http://www.scielo.br/scielo.php?pid=S0102-

64452000000200003\&script=sci abstract\&tlng=pt. Acesso em: 10 maio 2019.

BARBOSA, Gisele Heloise. O conselho municipal de transporte e trânsito de São Paulo (CMTT/SP): participação e mobilidade urbana. 2018. 237f. Tese (Doutorado em Ciência Política) - Universidade Federal de São Carlos, São Carlos, 2018.

BARBOZA, Estefânia Maria de Queiroz; KOZICKI, Katya. Judicialização da política e controle judicial de políticas públicas. Revista Direito GV, São Paulo, v. 15, p. 59-85, jan./jun. 2012. Disponível em:

http://bibliotecadigital.fgv.br/ojs/index.php/revdireitogv/article/view/23970. Acesso em: 10 maio 2019.

BOURDIEU, Píerre. Sobre a televisão: seguido de "A influência do jornalismo" e "Os jogos olímpicos". Rio de Janeiro: Zahar, 1997.

BRASIL. TRIBUNAL DE CONTAS DA UNIÃO. Relatório e parecer prévio sobre as contas do Governo da República. Brasília, 2010.

BUCCI, Maria Paula Dallari. Controle judicial de políticas públicas: possibilidades e limites. 2009. Disponível em: 
https://www.researchgate.net/publication/45236948 Controle judicial de politicas publ icas possibilidades e limites. Acesso em: 7 fev. 2019.

BIRD, Elizabeth; DARDENNE, Robert. Mito, registro e 'estórias': explorando as qualidades narrativas das notícias. In: TRAQUINA, Nelson (org.). Jornalismo: questões, teorias e "estórias". Lisboa: Veja, 1999.

COHEN, Joshua. Deliberation and democratic legitimacy. In: BOHMAN, James; REHG, William (ed). Deliberative democracy. Cambridge: Mit Press, 1997.

DWORKIN, Ronald. Los derechos en serio. Barcelona: Ariel, 2002.

DELLA PORTA, Donatella; DIANI, Mario. Social movements: an introdution. 2. ed. Malden: Blackwell Publishing, 2006.

ENTMAN, Robert. M. Framing: toward clarification of a fractured paradigm. Journal of Communication, v. 43, n. 4, 1993. Disponível em:

https://is.muni.cz/el/1423/podzim2018/POL256/um/Entman 1993 FramingTowardclarifi cationOfAFracturedParadigm.pdf. Acesso em: 10 maio 2019.

FORTUNATI, José. Entrevista ao poder e política. Portal UOL. Brasília, 18 dez. 2014. Disponível em: https://noticias.uol.com.br/cotidiano/ultimasnoticias/2014/12/18/2015comeca-com-onibus-mais-caro-em-capitais-diz-frente-de-prefeitos.htm. Acesso em: 10 maio 2018.

FREDERICO, Celso. Da periferia ao centro: cultura e política em tempos pós-modernos. Estudos Avançados [online], v. 27, n. 79, p. 239-255, 2013. Disponível em: http://www.scielo.br/scielo.php?pid=S010340142013000300017\&script=sci abstract\&tIng=es. Acesso em: 10 maio 2019.

GAMSON, William; WOLSFELD, Gadi. Movements and media as interacting systems. In: AMERICAN ACADEMY OF POLITICAL AND SOCIAL SCIENCE, 528., 1993, Newbury Park: Sage. Annals... p. 114-125.

GITLIN, Todd. The whole world is watching: mass media in the making and unmaking of the new left. Berkeley: University of California Press, 1980.

GOFFMAN, Erving. Frame analysis. Boston: Northeastern University Press, 1986.

GOHN, Maria da Glória. A sociedade brasileira em movimento: vozes das ruas e seus ecos políticos e sociais. Caderno CRH, v. 27, n. 71, p. 431-441, 2014. Disponível em: http://www.scielo.br/scielo.php?pid=S0103-

49792014000200013\&script=sci abstract\&tIng=pt. Acesso em: 10 maio 2019.

GOMIDE, Alexandre de Avila; GALINDO, Ernesto Pereira. A mobilidade urbana: uma agenda inconclusa ou o retorno daquilo que não foi. Estudos Avançados [online], v. 27, n. 79, p.27-39, 2013. Disponível em:

http://www.scielo.br/pdf/ea/v27n79/v27n79a03.pdf. Acesso em: 7 fev. 2019.

GREGORI, Lucio. Entrevista concedida à Rede Brasil Atual. 2013. Disponível em: https://www.redebrasilatual.com.br/cidadania/2013/06/transporte-gratuito-seriapossivel-se-estado-tivesse-outro-olhar-7635/ Acesso em: 2 jul. 2019.

KNEIB, Erika Christine. Mobilidade urbana e qualidade de vida: do panorama geral ao caso de Goiânia. Revista UFG, n. 2, Ano XIII, jul. 2012. Disponível em:

https://www.proec.ufg.br/up/694/o/12 09.pdf. Acesso em: 10 maio 2019.

KOVACH, Bill; ROSENSTIEL, Tom. Os elementos do jornalismo: o que os jornalistas devem saber e o público exigir. São Paulo: Geração Editorial, 2003.

KUNCZIK, Michael. Conceitos de jornalismo - Norte e sul. São Paulo: Edusp, 2001.

LIMA, P. P. F.; ALENCAR, J. L. O.; RIBEIRO, U. C.; CRUXEN, I. A.; SOUZA, C. H. L. de.

Conselhos nacionais: elementos constitutivos para sua insttucionalização. Texto 
para discussão / Instituto de Pesquisa Econômica Aplicada. Brasilia: Rio de Janeiro: IPEA, 2014.

LOCATTELLI, Piero. \#VemPraRua: as revoltas de junho pelo jovem repórter que recebeu passe livre para contar a história. São Paulo: Companhia das Letras, 2013.

MAHER, Michael. Framing: an emerging paradigm or a phase of agenda setting? In: REESE, Stephen; GANDY, Oscar (Jr.); GRANT, August E. (Ed). Framing public life. Mahwah: Lawrence Erlbaum, 2001. p. 83-94.

MENEZES, Antonio Simões. Jornalismo de resistência: apropriação das estratégias discursivas do campo midiático pela Revista Sem Terra. 2010. 155f. Dissertação (Mestrado) - Universidade Federal do Ceará, Fortaleza, 2010.

MOTTA, Luiz Gonzaga. Análise pragmática da narrativa jornalística. In: LAGO, Claudia; BENETTI, Marcia. Metodologia de pesquisa em jornalismo. Petrópolis: Vozes, 2010.

MOTTA, Luiz Gonzaga. Enquadramentos lúdico dramáticos no jornalismo: mapas culturais para organizar conflitos políticos. Intexto, Porto Alegre, v. 2, n. 17, p. 1-25, jul./dez. 2007. Disponível em: http://www.seer.ufrgs.br/intexto/article/download/3461/4134. Acesso em: 27 set. 2017.

PORTO, Mauro. Enquadramentos da mídia e política. In: RUBIM, Antonio Albinos Canelas (Org.). Comunicação e política: conceitos e abordagens. Salvador: Edufba, 2004.

RAMONET, Ignácio. A explosão do jornalismo: das mídias à massa de mídias. São Paulo: Publisher Brasil, 2012.

SÁDABA, Teresa. Framing: el encuadre de las noticias - el binomio terrorismo-medios. Buenos Aires: La Crujía, 2007.

SINGER, André. Brasil, junho de 2013: classes e ideologias cruzadas. Novos Estudos Cebrap, São Paulo, n. 97, p. 23-40, 2013. Disponível em:

http://www.scielo.br/scielo.php?script=sci arttext\&pid=S0101-33002013000300003. Acesso em: 10 maio 2019.

TAKEMOTO, Walter. Tarifa, mobilidade e exclusão social. São Paulo: Fundação Perseu Abramo, 2014. (Coleção O Que Saber).

THOMPSON, John B. A mídia e a modernidade: uma teoria social da mídia. Petrópolis: Vozes, 1998.

TRAQUINA, Nelson. Teorias do jornalismo: por que as notícias são como são.

Florianopolis: Insular, 2014.

TUCHMAN, Gaye. Making news - a study in the construction of reality. New York: The Free Press, 1980.

VASCONCELLOS, Eduardo Alcantara de. Mobilidade urbana: O Que Você Precisa Saber, livro eletrônico. São Paulo: Companhia das Letras, 2013.

XAVIER, Roseanne. O jogo da democracia: impressões sobre os protestos recentes no Brasil. Estudos de sociologia [online], v. 2, n. 19, 2013. Disponível em: https://periodicos.ufpe.br/revistas/revsocio/article/view/235578/2853. Acesso em: 10 maio 2019.

WOLTON, Dominique. Sobre la comunicación. Madrid: Acento Editorial, 1999. 